\title{
Needs Analysis of Augmentative and Alternative Communication Knowledge and Skills among Special Education Teachers for Malaysian Primary Schools
}

\author{
Mohd Hanafi Mohd Yasin, Shuhada Abdul Ghani", Suziyani Mohamed, Mohd Mokhtar Tahar
}

Universiti Kebangsaan Malaysia, 43600 Bangi, Selangor, Malaysia

Received July 30, 2020; Revised October 7, 2020; Accepted October 30, 2020

\section{Cite This Paper in the following Citation Styles}

(a): [1] Mohd Hanafi Mohd Yasin, Shuhada Abdul Ghani, Suziyani Mohamed, Mohd Mokhtar Tahar, "Needs Analysis of Augmentative and Alternative Communication Knowledge and Skills among Special Education Teachers for Malaysian Primary Schools," Universal Journal of Educational Research, Vol. 8, No. 11A, pp. 110 - 116, 2020. DOI: 10.13189/ujer.2020.082114.

(b): Mohd Hanafi Mohd Yasin, Shuhada Abdul Ghani, Suziyani Mohamed, Mohd Mokhtar Tahar (2020). Needs Analysis of Augmentative and Alternative Communication Knowledge and Skills among Special Education Teachers for Malaysian Primary Schools. Universal Journal of Educational Research, 8(11A), 110 - 116. DOI: 10.13189/ujer.2020.082114.

Copyright $\odot 2020$ by authors, all rights reserved. Authors agree that this article remains permanently open access under the terms of the Creative Commons Attribution License 4.0 International License

\begin{abstract}
Augmentative and alternative communication (AAC), also referred to as supplementary and replacement communication is critical to provide a communication channel for autistic students who find communicating via learning and facilitating the process in a class challenge. The communication competence of educators can promote and improve positive learning behaviours among students who have autism during the learning process. The objective of this research is to determine the augmentative and alternative communication skills possessed by special education teachers for autistic students in a classroom setting. The respondents of this study comprised of 73 Malaysian special education teachers. The pandemic has prompted the needs analysis questionnaire to be administered online to identify the knowledge and skills among the teachers. The findings reported the knowledge and skills among the respondents by percentage in the realization of AAC in a classroom setting. Findings based on the responses discovered an average level of the knowledge and skills among the teachers in the implementation of AAC which emphasizes the need for teachers to receive more extensive guidance.
\end{abstract}

Keywords Knowledge, Skills, Augmentative and Alternative Communication, Special Education Teachers

\section{Introduction}

The literature has reported minimal evidence on the utilisation of augmentative and alternative communication in classrooms by Malaysian special education teachers. Lack of training is not only an issue in Malaysia but is also evident in other countries such as Israel, United Kingdom, India, and the United States [7]. The National Education Policy in 2012 has designed policies to offer support and assistance in the implementation of augmentative and alternative communication to ensure the requirements of special needs students is fulfilled [34]. This plan was assigned to Malaysian special education teachers to incorporate these abilities throughout the learning and facilitating process in classrooms. This plan complies with the strategy reported in the Malaysian Education Blueprint (2013-2025) that are allocated as the leadership role in classrooms to the educators. Hence, educators must set positive examples and act as a mentor in setting a good example for students [19].

Studies with oral speech issues experience language challenges. The first challenge is that they are unable to articulate their needs verbally while the second challenge is that they experience difficulties in comprehending speech. Their educational development will be negatively affected if their difficulties are not addressed at the initial stages of schooling. Numerous issues associated with verbal 
communication will also be impacted which hinders autistic students from socializing with their school peers $[20,11]$. Students with autism find communicating at home and school challenging which impeded the development of positive behaviour in articulating their needs. American Psychiatric Association [3] characterized autism as mixed incompetence and it is often observed among kids less than years old. Neurological disorders are reported to cause autism as they disrupt brain function. Hence, students find communicating challenging at home and schools a difficult task.

Mustonen, Locke, Reichle, Solbrack and Lindgren [22] describe augmentative and alternative communication as an approach and instrument which improve current verbal communication skills. Hence, students who possess communication issues such as verbal communication require individual learning attention. National Research Council [23] categorized communication disability into two types which are attention merger and use of symbols. Porter [30] and Kuder [15] segregated AAC into verbal and non-verbal to substitute for sound and voice, communication disabilities, social difficulties, and behavioural problems. American Speech-LanguageHearing Association [3] refers to AAC as a communication method that utilizes sign language, gestures, photographs, electronic tools, written communication, and speech tools.

Research on communication channels among autistic individuals has been consistently conducted in the previous decade. In 2008, the Malaysian Psychiatric Association approximated that 1 out of 500 Malaysian children experience autism spectrum disorder and the data demonstrated that approximately 47,000 Malaysians are autistic whereby 4 or 5 people of 10,000 patients possess pure autism that contributes to the inability to comprehend their environment and can solely focus on themselves, and this estimation is predicted to increase annually. Nearly 70\% of autistic children experience mental retardation at various stages which contributes to reduced learning development, communication difficulties, behavioural issues, and communication disorders.

Numerous developed nations have incorporated the AAC method and the results reported a significant boost in the learning behaviour development among autistic students. Sigafoos and Mirenda [32] indicated that AAC encompasses symbol systems, communication techniques, and communication skills that are catered according to students' needs. Different AAC approaches can potentially be utilized for non-aided AAC such as body movement, sign language, facial expressions and fingerspell, and aided AAC which involves communicating by means of supplementary devices and high-tech communication system and pictorial communication system [8].

Non-aided AAC communication strategies do not necessitate external and mobile support devices. This strategy employs techniques which include sign language, facial expression, body movements, and verbal speech.
These techniques involve competence, sign language ability, memory, and creativity which can be challenging to master. Light \& Drager [18] mentioned that aided AAC is a strategy that employed support tools and involved thorough planning for management. There are various support electronic devices that are simple and multifaceted devices. The scope of support devices differs from simple to advance electronic tools that contain complicated systems. Real devices such as mobile phones, laptops, iPods, iPads, go talks, partner 4, hip talks, tech scan, tech talk, and voicePal Pro are involved in this method. This strategy is effective and flexible as it can be adjusted in accordance with the students' ability and difficulty. These techniques can reveal detailed messages than simply the students' language competence and also can be used remotely $[36,15]$.

\section{Problem Statement}

$\mathrm{AAC}$ is a technique that is accessible for everyone including individuals who experience verbal communication difficulties [20]. AAC is a communication technique which measures the adequacy and results of its implementation in a classroom setting [17]. Various communication aids that can used in classroom but have not been maximized which can be attributed to limited awareness, limited creativity, and lack of effort [29]. Not many studies show distinguished vocalizations used communicatively from those not used communicatively. [10].

It is generally known that special need students require significant commitment and patience from educators Haliza Hamzah [9] as teachers need to attract autistic students' attention who possess behavioural learning issues. Yet, teachers were not adequately trained on using images and sign language as a communication technique which subsequently influences student learning [24]. Furthermore, the utilization of this technique promotes social, cognitive, and motor development. Their self-reliance skill differs from normal children Sakinah, Nor Azizah and Muhammad Hibatullah [31].

Students with disabilities in special education classes have higher potential for success by adhering to the module which include co-operative teaching, collaborative learning, peer supervision, and advanced educational system programming that is thoroughly employed in the classroom context [1]. Students with autism possess a behavioural condition that differs from ordinary students. Multifaceted developmental problems concerning socialisation, communication, and behaviour skills are experienced by autistic students. Autistic students generally cannot socialize well with other students and always cause behavioural issues. Several students with autism have never interacted and do not possess the intention to conform to the standardized learning process in classrooms. 
Therefore, intervention and alternative augmentative communication skills are needed in enhancing oral communication competence to address failure to communicate among autistic students [33].

It is difficult to balance learning and facilitating without active communication in classrooms $[5,6]$. Autistic students tend to sleep in classrooms and do not participate in learning exercises which negatively affect their learning development. Noraini, Zamri \& Zahara [25] highlighted that many educators at cohesive special education for Integration classroom do not obtain widespread training and experience to tackle the communication skills issue between the educators and students. Mohd Zuri Ghani \& Aznan Che Ahmad [21] provided support by indicating that autistic students possess communication disorders, social interaction issues, sensory disorders, and emotional behaviours, and play patterns disruption. American Psychiatric Association [3] explained that autism disorders can be segregated into three primary categories of stereotyping and controlled social interaction, communication and behavioural distortion.

Special education teachers are required to comprehend and incorporate suitable communication technique throughout teaching and learning process which include utilizing technology that is suitable for the learning needs of autistic children who possess learning issues [26]. The primary aim of this research is to determine the extent of AAC communication knowledge and skills possessed by special education teachers.

\section{Research Methodology}

\section{Participants}

\section{Special Education Teachers}

Seventy-three teachers from the Malaysian Ministry of Education participated in this study. The respondents of this students are working as special education teachers for primary schools. The age of the respondents was between 21 and 51 years old. From the seventy-three respondents, fifty-eight were females while fifteen were males. The respondents are native speakers of the Malay Language and use English as a second or third language. All respondents possess at least a Bachelors' Degree of Education and their experiences ranges from 5 to 27 years. Thirteen teachers was reported to never have iPad as a high tech AAC while 27 reported never joining any AAC training throughout their services as a special education teacher.

\section{Data Collection}

\section{Questionnaire}

A survey research design was employed in this needs analysis study in determining special education teachers' level of AAC communication knowledge and skills. Creswell [16] indicated that surveys enable the direct collection of data and improve the generalisability of the data. Therefore, survey was chosen as questionnaires are convenient and enable simple distribution process. Three experts evaluated the instrument: 1. Special Education before distributed online. A total of 73 special education teachers with over 5 years of experience in the special education field responded to the online survey. The questionnaire is divided into 4 sections: A (Demographic), $\mathrm{B}$ (Knowledge on Augmentative and Alternative Communication), C (Features in Using AAC with the Help (Aided) High Technology That Can Improve Teaching and Learning Practices), D (Using AAC in a Learning and Facilitating process). The text of questionnaire was designed in the Malay Language to ensure a standardized understanding among the respondents. Online surveys were administered due to the Covid-19 pandemic and the findings will give chances to the teachers to get training and resources material mostly in rural areas.

\section{Findings}

This research investigated the level of knowledge among special education teachers in attaining the teaching skills during the learning and facilitating process. Early identification of students with verbal communication difficulties enables teachers to organize and offer alternatives to promote higher engagement and understanding throughout the learning and facilitating process [10].

This section explains the responses and is illustrated based on augmentative and alternative communication knowledge possessed by teachers in managing the learning difficulties experienced by autistic students. Table 1 further depicts the result. 
Table 1. ACC Knowledge Items among teachers of integrated special education for learning difficulties

\begin{tabular}{|c|c|c|c|}
\hline No. & Items & Yes $(\%)$ & No $(\%)$ \\
\hline 1. & $\begin{array}{c}\text { Can distinguish between augmentative and alternative } \\
\text { communication }\end{array}$ & 53 & 47 \\
\hline 2. & $\begin{array}{l}\text { Comprehend augmentative communication as a } \\
\text { replacement communication }\end{array}$ & 68 & 32 \\
\hline 3. & $\begin{array}{c}\text { Comprehend augmentative communication as a } \\
\text { supplement communication }\end{array}$ & 72 & 28 \\
\hline 4. & $\begin{array}{l}\text { Comprehend AAC can be employed without help } \\
\text { (unaided) }\end{array}$ & 33 & 67 \\
\hline 5. & $\begin{array}{l}\text { Comprehend that AAC can be employed with help } \\
\text { (aided) }\end{array}$ & 54 & 46 \\
\hline 6. & $\begin{array}{c}\text { Comprehend that low technology can be utilized to } \\
\text { employ aided AAC }\end{array}$ & 56 & 44 \\
\hline 7. & $\begin{array}{c}\text { Comprehend that aided AAC can be employed in the } \\
\text { classroom }\end{array}$ & 64 & 36 \\
\hline 8. & $\begin{array}{c}\text { Comprehend that unaided AAC can be implemented } \\
\text { outside the classroom }\end{array}$ & 56 & 44 \\
\hline 9. & Comprehend the use of smartphones & 97 & 3 \\
\hline 10. & Comprehend the use of iPad & 79 & 21 \\
\hline 11. & Comprehend the use of laptop & 97 & 3 \\
\hline 12. & Comprehend the use of Go-Talk & 32 & 68 \\
\hline 13. & Comprehend the use of communication boards & 56 & 44 \\
\hline 14. & Comprehend the use of communication books & 64 & 36 \\
\hline 15. & $\begin{array}{l}\text { Comprehend the use of Picture Exchange } \\
\text { Communication System (PECS) }\end{array}$ & 50 & 50 \\
\hline 16. & Can search for information using the Internet & 95 & 5 \\
\hline 17. & Can use Google application to search for images & 95 & 5 \\
\hline 18. & Can upload images online & 90 & 10 \\
\hline 19. & Can upload audio online & 71 & 29 \\
\hline 20. & Can upload videos online & 76 & 24 \\
\hline 21. & Can upload videos using YouTube & 72 & 28 \\
\hline
\end{tabular}

The results demonstrate a rise in Internet knowledge (95\%), smartphones (97\%), and competence in using the laptop (97\%). Yet, $47 \%$ of the respondents are unable to distinguish the difference between augmentative and alternative communication while $33 \%$ of the respondents comprehended that AAC can be employed without technological aids. A total of $68 \%$ of the respondents were not conscious of Go-Talk as a device that can be employed in aided AAC methods while only $50 \%$ of the respondents used the Picture Exchange Communication System (PECS) that was established to improve communication and minimize behavioural issues among students with autism. Results also revealed that the limitation of their knowledge and skills are caused by their reliance on computers and Internet search for the implementation of AAC in classrooms. Furthermore, thirteen respondents did not receive any exposure to high tech AAC.

\section{Discussion and recommendations}

United States National Research Council [6] identified that teacher training is the most delicate aspect of educating autistic students. Also, unsuitable teacher training is a significant problem that obstructs the delivery of satisfactory and professional educators specifically for students with autism. Students with Autism Spectrum Disorder (particularly classic autism) are challenging to teach. A traditional education system may be a disadvantage for the students and special education methods may be insufficient.

Hasnah, Mohd. Hanafi, Mohd. Mokhtar \& Norani [11] stressed that the limited knowledge of autism amongt special education teachers can be attributed to the minimal comprehensive feedback gained during the teaching practicum during university years. The results illustrated that the teachers received inadequate training on autism qualities, evaluating autistic students, performing teaching techniques for autistic students, participating in practical training with autistic students and working together with other professionals and parents. Hence, teachers must complete their training to fully comprehend autism guidelines which encompass communication, social abilities, support strategies, self-knowledge, interventions, 
and behavioural management. The application of AAC skills by primary school special education teachers in classrooms is examined in this study to solve the communication issue among autistic students. The learning growth of autistic students is depend on the quality of communication between teachers and students which cements the importance of teachers' communication skill [31].

Centre for Disease and Control Prevention published a report in 2010 that elucidated that 1 in 110 children in the United Stated are autistic [12]. This issue escalated quickly within a span of five years whereby 2015 depicted a surge of 1 in 68 children who are autistic. Hazahamima $\&$ Norshidah [13] identified that students with autism were not attracted to conventional PdPC sessions performed in classrooms. Autistic students were identified to disregard PdPC sessions by exhibiting defiant actions such as walking, trembling hands, crying, and daydreaming. Special education teachers are necessitated to prepare themselves with optimal communication skills to facilitate positive and effective learning outside and inside a classroom [31].

Minimal information on students with autism has hindered meaningful teaching and learning [26]. This issue has become very critical to the extent that autistic students are labelled as stupid since the teachers do not know suitable methods to educate these students [28]. Many autistic students experience communication issues, imagination problems, and social interaction disorders. Hence, the development of autistic students is weaker than the typical students. Nevertheless, the extent of this condition varies according to an individual [21,28].

Suitable behavioural control, social and communication skills are needed for autistic students to obtain meaningful learning $[26,28,21]$. Recurrent issues in the classroom throughout the learning and facilitating process are uncontrolled action, uncontrolled behaviour, and undeveloped communication $[35,21,28])$. There are also other conditions whereby autistic students cannot articulate even when they can communicate well, and this condition is referred to as 'mutism' [31, 37]. Students with autism involve teachers with distinct teaching abilities to aid and offer students the rudimentary support skills in communication, behaviour, and socialisation [2]. Hence, students' communication skills must be encouraged in order to promote interest to participate in the learning and facilitating session.

Poor awareness and unsuitable teaching methods may influence students' achievement. Therefore, a detailed understanding of suitable teaching skills for autistic students is critical in order to initiate the learning and facilitating session and to comprehend their learning behaviour in classrooms. Incorporating augmentative and alternative communication strategies such as sign language, gestures, and picture swapping during learning and facilitating process can be established through formal training and seminars. Incorporating useful communication methods and techniques will assist teaches to promote and aid students to explain their message. This research evaluated the proficiency of AAC communication knowledge and skills among special education teachers throughout the learning and facilitating session in classrooms and determine whether AAC could solve the communication issues among autistic students.

\section{Conclusions}

Surveys demonstrated that high technologies tools or software are required when AAC training is provided to Malaysian special education teachers. It is critical to developing teaching modules and training to sharpen the knowledge and skills among special education teachers. Teachers' proficiency in augmentative and alternative communication skills can assist they in mitigating communication challenges among students with learning difficulties issues, specifically students with autism who experience speaking issues throughout the learning and facilitating session in classrooms. Children with autism can improve their learning ability through the AAC method. Proficiency in aided and non-aided AAC communication skills proficiency includes mastery of verbal and nonverbal communication. Special education teachers who can assist students using AAC have higher potential to determine students' ability and communication growth [7]. AAC communication skills processes and instruments are the finest alternatives for people who experience difficulties in articulating their needs. Nevertheless, if these procedures and instruments are not maximized, no benefits can be obtained by the teachers and students. Hence, this study aims to further develop training AAC programmes at Malaysian primary schools.

\section{Acknowledgements}

The authors would like to convey our sincerest gratitude to Faculty of Education Universiti Kebangsaan Malaysia Research Grant (GG-2019-063) and the participants for providing useful responses for this study.

\section{REFERENCES}

[1] Abbeduto, L., Seltzer, M.M., Shattuck, P., Krauss, M.W., Orsmond, G. \& Murphy, M.M. 2004. Psychological WellBeing and Coping in Mothers of Youths with Autism, Down Syndrome, orFragile X Syndrome. American Journal on Mental Retardation 109(3): 237.

[2] Alexander, J.L., Ayres, K.M. \& Smith, K.A. 2015. Training teachers in evidence-based practice for individuals with 
Autism Spectrum Disorder: A review of the literature. Teacher Education and Special Education 38(1): 13-27.

[3] American Psychiatric Association. 2016. Diagnostic and statistical manual of mental disorders. Psychiatric News 51(9): 1-1.

[4] American Speech-Language-Hearing Association. 2015. U.S. Education Department says ABA is not the only ASD treatment. The ASHA Leader (20(12).

[5] Bernier, R.A., Dawson, G., Nigg, J.T. 2020. What science tell us about autism spectrum disorder. The Guilford Press: New York.

[6] Cooper, P. \& S.C.J. 2007. Communication for the classroom teacher. 8th ed. United States: Pearson Education, Inc.

[7] Council, N.R. 2001. Educating Children with Autisme. National Academy of Sciences (Pnyt.) hlm. Committee. National Academies Press.

[8] Da Fonte, M.A. \& Boesch, M.C. 2016. Recommended Augmentative and Alternative Communication Competencies for Special Education Teachers. Journal of International Special Needs Education 19(2): 47-58.

[9] Ganz, J.B. 2014. Aided Augmentative Communication for Individuals with Autism Spectrum Disorders.

[10] Gül Kahveci1, Serin Nergüz Bulut. 2019. Shaping Vocal Stereotypy in Autism Spectrum Disorder: A Non-Aversive Communication Teaching Technique, Universal Journal of Educational Research 7(6): 1448-1457

[11] Haliza Hamzah, J.N. 2014. Classroom Management and Behaviour. Pendi Series. Shah Alam, Selangor: Oxford Fajar Private Ltd.

[12] Harding, C., Lindsay, G., O’Brien, A., Dipper, L. \& Wright, J. 2011. Implementing AAC with children with profound and multiple learning disabilities: A study in rationale underpinning intervention. Journal of Research in Special Educational Needs 11(2): 120-129.

[13] Hasnah, T., Mohd. Hanafi, M.Y., Mohd. Mokhtar, T. \& Norani, S. 2010. Levels of Training, Knowledge and Confidence of Special Education Teachers on Children with Autism. Malaysian Journal of Education 35(1): 19-26.

[14] Hasnah Toran, Salmah Bujang, F.C. 2013. Structured Teaching Children with Autism Education Series. Bangi: Universiti Kebangsaan Malaysia.

[15] Hazahamima Miskam dan Norshidah Mohd Salleh. 2016. Use of Ipad in Dealing with Challenging behaviour of Children with Autism Spectrum Disorder (ASD) Students in the Classroom. International Seminar on Special Education of the Southeast Asian Region 6 Series: 745-751.

[16] Jang, J., Dixon, D.R., Tarbox, J. \& Granpeesheh, D. 2011. Symptom severity and challenging behavior in children with ASD. Research in Autism Spectrum Disorders 5(3): 10281032 .

[17] Jay Kuder, S. 2003. Teaching Students with Language and Communication Disabilities. Second Edition.

[18] John W. Cresswell. 2014. Research Design: Qualitative, Quantitative, and Mixed Methods Approaches. 4th ed. United States: SAGE Publications Ltd.
[19] John W. Santrock. 2011. Educational Psychology. 5th ed. New York: McGraw-Hill Companies Inc.

[20] Light, J. C., \& Drager, K.D. 2002. Improving the design of augmentative and alternative technologies for young children. Assistive Technology, 14, 17-32. Assistive Technology (14): 17-32.

[21] Malaysia Education Blueprint, M. 2013. Malaysia Education Blueprint 2013 - 2025. Education 27(1): 1-268.

[22] Millar, D.C., Light, J.C. \& Schlosser, R.W. 2006. The Impact of Augmentative and Alternative Communication Intervention on the Speech Production Disabilities: A Research Review. Journal of speech, language, and hearing research: JSLHR 49(April): 248-264.

[23] Mohd Zuri Ghani \& Aznan Che Ahmad. 2014. Teaching methods and strategies for children with special needs by Mohd Zuri Ghani, Aznan Che Ahmad. Universiti Sains Malaysia.

[24] Mustonen, T., Locke, P., Reichle, J., Solbrack, M., \& Lindgren, A. 1991. An overview of augmentative and alternative communication. In J. Reichle, J. York, \& J. Sigafoos (Eds.), Implementing augmentative and alternative communication: Strategies for learners with severe disabilities. Baltimore: Paul H. Brookes Publishing Co.

[25] National Research Council Educating Children with Autism. Committee on Educational Interventions for Children with Autism. Catherine Lord and James P. McGee, eds. Division of Behavioral and Social Sciences and Education. Washington, DC: National Academy P. 2001.

[26] Noor Aini Ahmad, \& N.H.A.H. 2015. The level of knowledge of special education teachers when managing students with learning difficulties. Asia Pacific Journal of Educators and Education 30: 73-88.

[27] Noraini, A., Zamri, M., \& Zahara, A. 2012. Communication Skill Teaching for Severe Learning. $g$ Disabilities Pupils. Malay Language Educational Journal. 2(2): 11-18.

[28] Norfishah Mat Rabi. 2015a. Secrets and uniqueness of the personality of children with autism in Malaysia. Publisher Universiti Sains Malaysia (Editor.) Penang.

[29] Norfishah Mat Rabi. 2015b. Secrets and uniqueness of the personality of children with autism in Malaysia. Universiti Sains Malaysia. Penang.

[30] Norfishah Mat Rabi. 2016. Transformation of Education for Students with Disabilities. Tanjong Malim, Perak: Sultan Idris Education University.

[31] Pilgrim, J., Bledsoe, C. \& Reily, S. 2012. New Technologies in the Classroom. Delta Kappa Gamma 2010(2006): 16-23.

[32] Porter, L. 2002. Educating Young Children with Special Needs. British Li. London: Paul Chapman Publishing.

[33] Sakinah Idris, Nor Azizah Nurdin, M.H.R. 2014. Children with autism: Therapy and Support. Universiti Teknologi Mara (Editor). Kuala Lumpur: Haji Jantan Publication Private Ltd.

[34] Sigafoos, J and Mirenda, P. 2002. Strengthening communicative behaviors for gaining access to desired items and activities, Exemplary practices for beginning communicators. J Reichle,. Baltimore: Paul H. Brookes 
Publishing Co.

[35] Son, S.-H., Sigafoos, J., O’Reilly, M. \& Lancioni, G.E. 2006. Comparing two types of augmentative and alternative communication systems for children with autism. Pediatric Rehabilitation 9(4): 389-395.

[36] Tobergte, D.R. \& Curtis, S. 2013. National Education Policy. Malaysian Education Ministry.
[37] Trevarthen, C. Aitken, K. Papoudi, D. \& Robarts, J. 1996. Children with autism: Diagnosis and interventions to meet their needs. London: Jessica Kinglsley.

[38] Zeng, N., Zou, S., Zheng, G., Ou. Y., Tong, T. 2020. Artificial intelligence for medical image analysis of neuro imaging data: Frontier in Neuro Science Press.

[39] Zlatanova, S. 2002. Augmented Reality Technology: 77. 